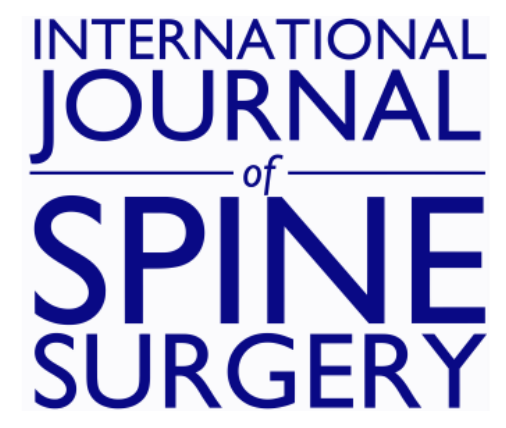

\title{
Infection after anterior spinal fusion for idiopathic scoliosis using the Cotrel-Dubousset-Hopf system: A clinical case series of three patients
}

Jaap J. Tolk, Paul C. Willems, Ilona M. Punt, Lodewijk W. van Rhijn and André van Ooij

Int J Spine Surg 2016, 10 ()

doi: https://doi.org/10.14444/3002

http://ijssurgery.com/content/10/2

This information is current as of April 26, 2023.

Email Alerts Receive free email-alerts when new articles cite this article. Sign up at:

http://ijssurgery.com/alerts

The International Journal of Sphing Surgerthttp://ijssurgery.com/ by guest on April 26, 2 2397 Waterbury Circle, Suite 1, 


\section{Infection after anterior spinal fusion for idiopathic scoliosis using the Cotrel-Dubousset-Hopf system: A clinical case series of three patients}

Jaap J. Tolk, MD, 1 Paul C. Willems, MD, PhD, 2 Ilona M. Punt, PhD, 2 Lodewijk W. van Rhijn, MD, PhD, 2 André van Ooij, MD, PhD

${ }_{1}^{1}$ Máxima Medical Centre, Department of Orthopedic Surgery, Eindhoven, the Netherlands, 2 Maastricht University Medical Centre, Department of Orthopedic Surgery, Maastricht, the Netherlands, ${ }^{2}$ VieCuri Medical Centre, Department of Orthopedic Surgery, Venlo, the Netherlands

\section{Abstract}

\section{Background}

Three patients with late-onset infection after multilevel instrumented anterior spinal fusion for idiopathic scoliosis, using the Cotrel-Dubousset-Hopf $(\mathrm{CDH})$ system, are presented. The $\mathrm{CDH}$-system is an anterior instrumentation with high biomechanical stability and rigidity, ensuring a stable primary fixation. Unlike after posterior spinal fusion, infection after anterior spinal fusion (ASF) for idiopathic scoliosis has rarely been reported.

Methods

The files of three patients who developed an infection after ASF for scoliosis using the CDH-system, were reviewed. The clinical presentation and diagnostic and therapeutic options are discussed.

Results

All three patients had a late-onset infection of the $\mathrm{CDH}$-system, which was difficult to diagnose because of nonspecific symptoms. Radiographs and technetium bone scan appeared to be of low value. When an abscess was present, this could accurately be diagnosed with MRI or CT imaging. Operative treatment with implant removal and antibiotic therapy was successful in all cases.

\section{Conclusion}

Late onset infections after ASF using the $\mathrm{CDH}$-system presented with few and nonspecific symptoms. The clinical presentation was mainly characterized by vague abdominal- or back-pain after an interval of normal postoperative recovery, moderately raised infection parameters and inconclusive findings with imaging modalities. As treatment, implant removal, debridement and parenteral antibiotics are recommended. It should be noted though that implant removal poses serious risks for vascular and visceral structures.

KEYWORDS: SCOLIOSIS, ANTERIOR SPINAL FUSION, INFECTION, COTREL-DUBOUSSET-HOPF SYSTEM

VOLUME 10 ARTICLE 2 DOI: 10.14444/3002

\section{Introduction}

For surgical correction of idiopathic scoliosis, an anterior, posterior, or combined approach can be used. The anterior approach, as developed by Dwyer ${ }^{1}$ and modified by Zielke, ${ }^{2}$ is considered to be suitable for deformity correction in lumbar and thoracolumbar curves based on the idea that scoliotic deformity arises from the anterior vertebral column. ${ }^{1,23}$ In 1995, Hopf et al. ${ }^{4}$ presented the Cotrel-Dubousset-Hopf $(\mathrm{CDH})$ system as an anterior spinal fusion (ASF) instrumentation with high biomechanical rigidity and stability, ensuring a primarily stable fixation. ${ }^{3,45}$ This system consists of stainless steel blocks that are at- tached to the lateral side of the vertebral body, with two cancellous screws. A 6 millimetre $(\mathrm{mm})$ rod is inserted into the posterior slots of the vertebral blocks, rotated to correct the scoliotic curve and a $4 \mathrm{~mm}$ anterior rod is implanted to maintain the correction. ${ }^{3,4}$ An interbody bony fusion is always added.

Studies by Hopf et al. ${ }^{3}$ and Benli et al. ${ }^{4}$ reported the use of the $\mathrm{CDH}$-system for anterior thoracolumbar scoliosis correction in 16 and 26 patients with an idiopathic scoliosis respectively. Complications were rare and no infections were reported during a mean follow-up of 26.5 and 32.8 months, respectively. ${ }^{3,4}$ In general, infection after ASF for idiopathic scoliosis is 
very uncommon and has hardly been described before in the literature..$^{6,7,8,9}$

From 1999 to 2002 the CDH-system was used for ASF in sixteen consecutive patients with idiopathic scoliosis, in the Maastricht University Medical Centre. For bony interbody fusion morselised ribgraft, harvested during the thoraco-phrenico-lumbotomy, was used. Interbody cages were not utilized. Postoperative spinal immobilization with a brace was applied for 6 months. In three of these 16 cases of multilevel anterior scoliosis surgery using the $\mathrm{CDH}$ system, the postoperative course was complicated by infection.

\section{Cases}

An overview of the patients' characteristics is listed in Table 1, and a summary of the symptoms and diagnostic findings is presented in Table 2 .

\section{Case 1}

A 16-year old female underwent a T10-L3 ASF in December 1999 for a progressive Lenke type 6C idiopathic scoliosis with a $59^{\circ} \mathrm{Cobb}$ angle. The postoperative recovery was quick and uneventful. Four years after surgery she developed back-pain in the thoracolumbar region. Imaging with plain radiographs and CT showed no signs of dislocation, implant failure or loosening of screws. The pain was considered to be caused by impingement of the screw tips against the ribs or possibly due to the placement of one of the screws in the Th9-10 disc. The patient received transcutaneous electrical nerve stimulation (TENS) for pain relief.

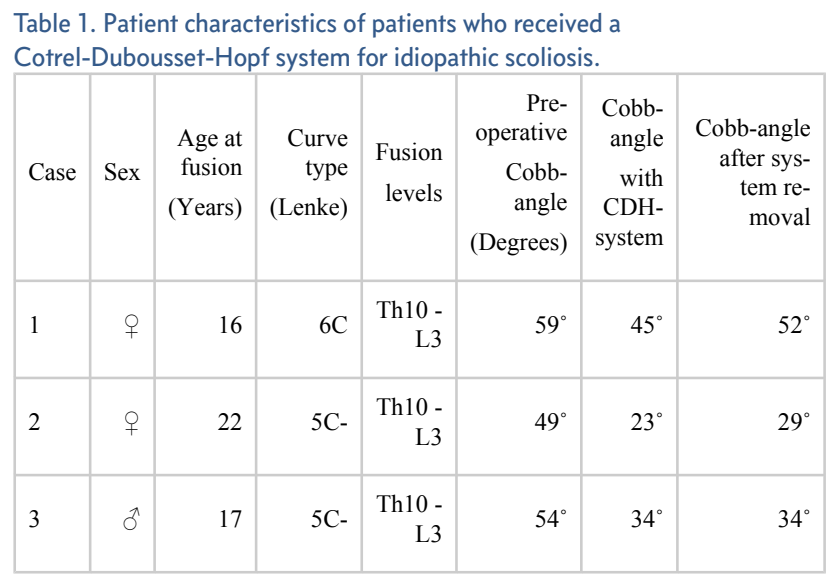

Five and a half years after surgery, the back pain worsened and expanded to the left sacroiliac joint region. The patient had no fever and was not ill. Erythrocyte Sedimentation Rate (ESR) was $45 \mathrm{~mm} / \mathrm{h}$, C-reactive protein (CRP) $49 \mathrm{mg} / \mathrm{l}$ and White Blood Cell Count (WBC) 12,3×109/1. Bone-scintigraphy and Magnetic Resonance Imaging (MRI) showed no abnormalities and infection of the $\mathrm{CDH}$-system was therefore considered to be unlikely.

Half a year later, early 2006, a painful swelling in the left flank developed and gradually increased in size to 8 by $5 \mathrm{~cm}$. MRI showed an abscess, which was drained percutaneously, cultures were taken and Flucloxacilin 6x1000mg i.v. was started. It was decided to remove the $\mathrm{CDH}$-instrumentation. At surgery clear signs of infection were seen, with large amounts of fibrotic and granulation tissue. A postoperative haematothorax required revision surgery, with insertion of an additional drain. This resulted in full pul-

\begin{tabular}{|c|c|c|c|}
\hline $\begin{array}{l}\text { Symptoms \& find- } \\
\text { ings }\end{array}$ & Case 1 & Case 2 & Case 3 \\
\hline $\begin{array}{l}\text { Late onset back- or } \\
\text { abdominal pain }\end{array}$ & Yes & Yes & No \\
\hline Fever & No & No & No \\
\hline $\begin{array}{l}\text { Local signs of infec- } \\
\text { tion }\end{array}$ & $\begin{array}{r}\text { Painful } \\
\text { swelling }\end{array}$ & $\begin{array}{r}\text { Painful } \\
\text { swelling }\end{array}$ & Fistula \\
\hline \multirow{3}{*}{$\begin{array}{l}\text { ESR, CRP \& WBC } \\
\text { on presentation }\end{array}$} & ESR 43 & ESR 32 & ESR 24 \\
\hline & CRP 49 & CRP 24 & CRP 30 \\
\hline & WBC 12,3 & WBC 8,9 & WBC 10 \\
\hline Suspect radiographs & No & $\begin{array}{r}\text { Screw loos- } \\
\text { ening }\end{array}$ & No \\
\hline $\begin{array}{l}\text { Bonescintigraphy in- } \\
\text { dicating infection }\end{array}$ & No & Yes & No \\
\hline $\begin{array}{l}\text { CT- or MRI-scan } \\
\text { showing abscess or } \\
\text { fistula }\end{array}$ & Yes & Yes & Yes \\
\hline $\begin{array}{l}\text { Time from onset of } \\
\text { symptoms to diagno- } \\
\text { sis }\end{array}$ & 29 months & 2 days & 4 months \\
\hline $\begin{array}{l}\text { Time between im- } \\
\text { plant placement and } \\
\text { removal }\end{array}$ & 78 months & 59 months & 106 months \\
\hline $\begin{array}{l}\text { Macroscopic findings } \\
\text { on revision surgery }\end{array}$ & $\begin{array}{r}\text { Fibrotic and } \\
\text { granulation } \\
\text { tissue }\end{array}$ & $\begin{array}{r}\text { Pus, granula- } \\
\text { tion tissue, } \\
\text { abscess }\end{array}$ & $\begin{array}{r}\text { Fibrotic and granu- } \\
\text { lation tissue, pus- } \\
\text { pocket }\end{array}$ \\
\hline Identified pathogen & P. Acnes & $\begin{array}{r}\text { No pathogen } \\
\text { identified }\end{array}$ & S. Aureus \\
\hline
\end{tabular}


monary recovery. The cultures showed a Propionibacterium Acnes bacteria, and antibiotics were switched to Clindamycin $4 \times 600 \mathrm{mg}$ orally for ten weeks.

One and a half year after implant removal the pain had resolved completely and the infection parameters were normalized. The residual scoliotic curve had progressed from a Cobb angle of $45^{\circ}$ to $52^{\circ}$. A protruding abdominal wall on the left side, caused by paralysis of the left abdominal muscles, persisted.

\section{Case 2}

In February 2002, a 22-year old female underwent a Th10 to L3 ASF for a Lenke type 5C-scoliotic curve with a $49^{\circ} \mathrm{Cobb}$ angle. The postoperative course was uneventful. In august 2006 she started to complain of back pain, radiating to the left thigh. The pain was continuously present and aggravated by lying down. She was not feeling ill, had no fever and there were no neurological abnormalities. Laboratory findings showed an ESR of 32, CRP of 24 and WBC of 8.9. Bone-scintigraphy showed increased uptake around the surgical site. Suspecting a low-grade infection, antibiotic treatment was started with $4 \times 500 \mathrm{mg}$ Flucloxacillin orally. However, laboratory findings worsened and the patient developed a red, painful swelling in the left lumbar region. Plain radiographs showed loosening of the distal screws and a CT scan showed a fluid collection of 3 by $5 \mathrm{~cm}$ around the distal part (L2-L3) of the rods. It was decided to remove the infected instrumentation. During revision surgery extensive granulation tissue and a big abscess in the left psoas muscle were found. Cultures showed no growth; even after prolonged cultivation no bacteria could be identified. Antibiotic treatment consisted of two weeks of Amoxicillin/Clavulanic acid $3 \times 1000 / 200 \mathrm{mg}$ i.v., followed by ten weeks oral Clindamycin 3x600mg.

During postoperative recovery the patient suffered from fatigue and back pain. These complaints gradually disappeared in six months time and the infection parameters returned to normal. The residual scoliotic curve had progressed from $23^{\circ}$ to $29^{\circ}$ before reaching a stable situation six months after removal of the $\mathrm{CDH}$-system.

\section{Case 3}

An instrumented T10-L3 ASF, for a Lenke type 5Cscoliosis with a $54^{\circ} \mathrm{Cobb}$ angle, was performed in January 2002 in a 17-year old male. Seven years later, in September 2009, he was referred to our department with a fistula on the left flank, about $10 \mathrm{~cm}$ lateral to the incision of the index surgery (Figure 1). The patient was not ill, had no fever and no back- or abdominal pain. Laboratory findings showed an ESR of 24, CRP of 30 and WBC of 10.0. Plain radiographs and a bone scintigraphy did not show signs of loosening or infection of the $\mathrm{CDH}$-system. A CTfistulography showed that the fistula continued retroperitoneally to the spinal instrumentation, with an adjacent $7 \mathrm{~cm}$ long cavity (Figure 2). Surgical removal of the $\mathrm{CDH}$-system followed. To reach the spine, the left ureter had to be mobilized from scar tissue. Cultures grew a Staphylococcus Aureus, for which the patient was treated with Cefazolin $4 \times 1000 \mathrm{mg}$ i.v.

The infection parameters improved gradually, but the wound kept producing serous fluid. Creatinineanalysis of this fluid was positive indicating urine leakage, caused by ureter injury presumably due to manipulation during surgery. Although the insertion of a double-J catheter and a nephrostomy by the urologist failed, the leakage stopped spontaneously, as confirmed by ultrasound, CT-IVP and a renogram. The patient rapidly recovered and was discharged after three weeks with Clindamycin 3x600mg orally for two months. The scoliotic curve that had a Cobb angle of $34^{\circ}$ with the CDH-system in situ, did not

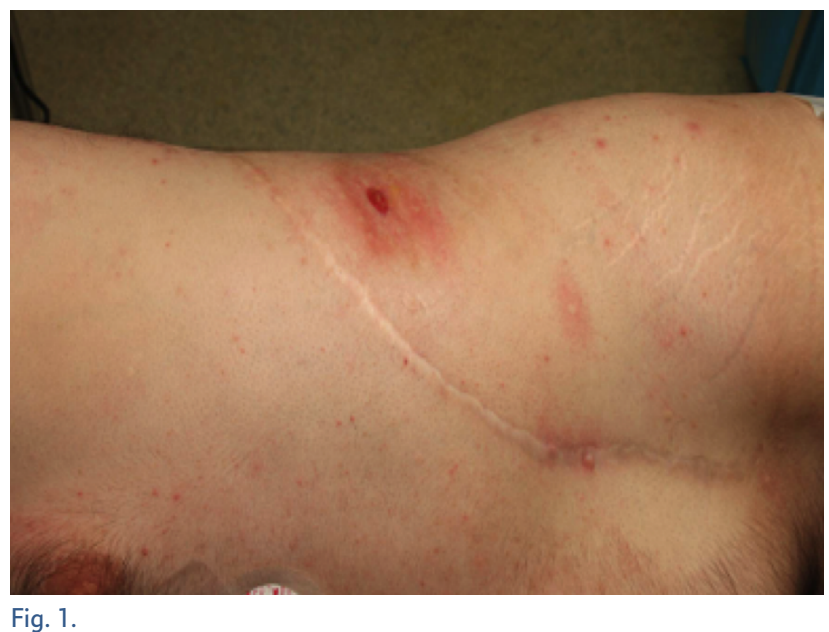


progress in the first year after surgery.

\section{Discussion}

Complications in surgical treatment of idiopathic scoliosis are encountered in about $5.7 \%$ to $15.4 \%$ of the patients. The use of an anterior or a posterior approach does not appear to be of influence on the overall complication rate. ${ }^{6,7}$ Infections after PSF for idiopathic scoliosis are reported in $1.4 \%$ to $5 \%$ of cases, whereas after ASF these percentages are reported to be considerably lower; $0 \%$ to $0.2 \%{ }^{7,10,11}$ The low postoperative infection rates after ASF may be due to less intraoperative soft tissue damage and devascularisation as compared to posterior procedures. ${ }^{12}$

In contrast to the previously reported infection rates after ASF, we found a relatively high infection rate in our CDH-series, with 3 out of 16 patients affected. This is an exceptionally high infection rate for anterior instrumented spinal fusion. A possible explanation is a break in sterile technique within the operation theatre. Review of the local complication registration database of the department of Orthopaedic surgery did not show an increased infection rate for instrumented spinal surgeries or total hip or knee arthroplasty in the years 1999-2002 when the CD-Hopf system was implanted in our clinic. There were no breaks in sterile technique described either. The

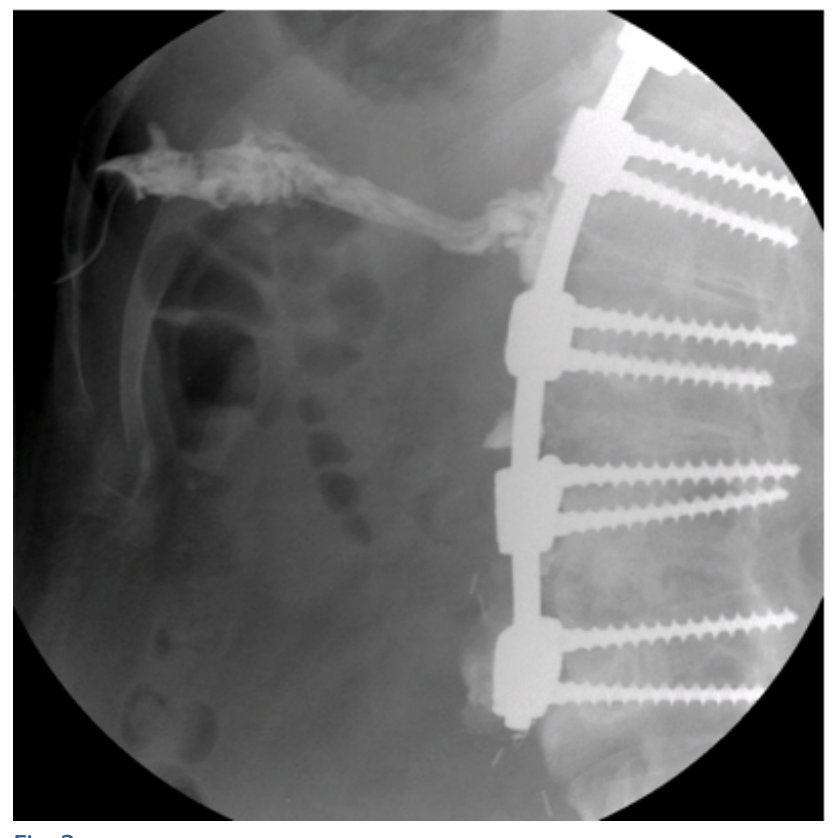

Fig. 2. most likely sources of infection are intra-operative inoculation or hematogenous spreading of the pathogens. ${ }^{13}$ The $P$. Acnes bacterium, as cultured in the first case, is known to cause delayed infection with a long interval between inoculation of the pathogen and onset of symptoms. ${ }^{14}$ The insidious onset in the second case suggests a low virulent microorganism as the causative agent as well. The cultures probably were unreliable due to start of antibiotic treatment, before representative cultures were obtained. In the third case, S. Aureus was the causative bacterium, suggesting a hematogenous origin. These findings confirm the need for obtaining multiple representative intra-operative cultures and prolonged culturing if initially no micro-organism is found.

Implant factors influence the infection risk as well. In comparison to other ASF-systems the $\mathrm{CDH}$-system is relatively bulky. This may increase the risk of damaging vital structures due to friction with the implant. ${ }^{15}$ In PFS increasing volume of the implant has been proposed as a risk factor for higher infection rates. ${ }^{16}$ In anterior procedures this relation seems less obvious. The spinal implant alloy is considered to influence the development of late onset infection as well. Stainless steel implants, as the $\mathrm{CDH}$ system, seem more subject to late post-operative infection as compared to titanium systems. The latter having greater bone adhesion on the hardware, resulting in the production of thinner biofilm. ${ }^{13,17}$

To our knowledge, only two reports have addressed the clinical presentation of infection after ASF and instrumentation. ${ }^{8,9}$ Robertson and Taylor described three cases of late onset infection after anterior scoliosis correction using Dwyer instrumentation. ${ }^{8}$ Two of these patients presented with malaise and an elevated ESR level but none of the patients experienced back pain. One patient developed a draining sinus in the groin and one patient an abscess in the groin, both originating from the spinal fixation. ${ }^{8}$ Van Luijk and de Nies reported one case of infection after anterior scoliosis surgery, with scoliosis curve progression and a hip flexion contracture one year after surgery. ${ }^{9}$ The patient did not experience back or abdominal pain and the infection parameters were within normal range. ${ }^{9}$ We found similar clinical presentations as Robertson and Taylor, with absence of 
specific symptoms (Table 2). ${ }^{8}$ Infection was suspected, but only discovered after formation of a fistula or an abscess. Late onset infections after PSF often present with diffuse back-pain after an interval of normal postoperative recovery, malaise, slightly elevated infection parameters and absence of fever. ${ }^{12,16,18,19,20} \mathrm{In}$ contrast with late PSF infections, after ASF the pain, if present, can be poorly localized and may even mimic an abdominal problem.

The role of diagnostic imaging in infection after spinal fusion and instrumentation has not been clearly established. ${ }^{8,912,19,21}$ Plain radiographs may show a pseudarthrosis or screw loosening associated with infection. Technetium bonescan, Gallium-scan and Indium-111-labeled leukocyte scintigraphy may be useful diagnostic tools, but have been reported to have high false negative rates. ${ }^{12,15,21}$ MRI with gadolinium enhancement and CT have $91 \%$ sensitivity when a fluid collection or abscess is present..$^{21}$ Robertson and Taylor reported negative findings with plain radiographs and Technetium bone scan. ${ }^{8}$ In their patient with a draining sinus, the infection was confirmed with CT scan and Gallium-scan. ${ }^{8}$ Van Luijk and de Nies reported negative or inconclusive findings with initial plain radiographs, CT and MRI imaging. After one year, MRI showed the presence of an abscess, confirming the suspected infection. ${ }^{9}$ In our series initial imaging was inconclusive in two of the three cases (Table 2). Only in case 2 plain radiographs showed clear loosening of the screws, indicating infection. In two out of three cases a bone scintigraphy failed to show signs of infection. Only if patients developed an abscess or fistula, infection could be confirmed by CT or MRI.

The recommended treatment for delayed infection after PSF for scoliosis, consists of surgical debridement, lavage and implant removal, followed by culture guided antibiotic treatment. ${ }^{16,18,20,21,22,23}$ For infections after ASF comparable treatment has been suggested. ${ }^{8,9}$ We treated our patients with removal of the instrumentation, irrigation and debridement. The same approach as the index surgery was used in case 1 and 2 , in case 3 only the lumbotomy part of the incision was used. Implant removal followed by two to three weeks parenteral antibiotics, and six to ten weeks oral antibiotics. After treatment the infection was cleared in all three cases. An alternative treatment option might be suppressive antibiotic treatment, with drainage of abscesses if present. Thus evading the risks of revision surgery. Because of biofilm formation in late onset infection, eradication without implant removal cannot be expected with this strategy. The indefinite administration of antibiotics might induce bacterial resistance and in delayed infection after posterior spinal fusion, this treatment strategy showed to fail in $67 \%$ of cases. ${ }^{18}$

Complication rates for revision anterior lumbar surgery are reported to be three to five times higher as compared to primary interventions. ${ }^{24}$ There is an additional risk for injury to vascular and visceral structures by the formation of scar tissue from the original exposure. ${ }^{25}$ Ureter injury after revision anterior spinal surgery, as occurred in patient 3 , has been reported in 0,3 to $0,5 \%$ of cases. ${ }^{24}$ Removal of the instrumentation may increase the scoliotic curve. When PSF instrumentation is removed, even when solid fusion is present, more than 50 percent of cases have curve progression exceeding ten degrees. ${ }^{23,24}$ In our series all patients had complete fusion at the time of implant removal, and there was no visible motion between segments upon manual intraoperative testing. Therefore, solid fusion was assumed to be present. We observed no, or only mild curve progression after $\mathrm{CDH}$-system removal of 0 to $7^{\circ}$ before a stable situation was reached.

\section{Conclusion}

Infection after ASF for idiopathic scoliosis is uncommon and has rarely been described before in the literature. The diagnosis of infection can be difficult because there are few and often non-specific symptoms. Clinical presentation is mainly characterized by vague abdominal- or back-pain after an interval of normal postoperative recovery. In our series all three patients had a moderately raised ESR. Imaging with plain radiographs and technetium bone scan was inconclusive. When an abscess was present, this could accurately be diagnosed with MRI or CT imaging. For late-onset infections implant removal is recommended. However, this poses serious risks for vascular and visceral structures and mild curve progression should be anticipated. 


\section{References}

1. Dwyer AF. Anterior instrumentation for scoliosis. Isr J Med Sci. 1973 Jun;9(6):805-12.

2. Zielke K, Stunkat R, Beaujean F. Ventrale derotations-spondylodesis. Arch Orthop Unfallchir. 1976;85(3):257-77.

3. Hopf CG, Eysel P, Dubousset J. Operative treatment of scoliosis with Cotrel-Dubousset-Hopf instrumentation. New anterior spinal device. Spine. 1997;22(6):618-27.

4. Hopf A, Eysel P, Dubousset J. CDH: preliminary report on a new anterior spinal instrumentation. Eur Spine J. 1995;4(3):194-9.

5. Benli IT, Akalin S, Kis M, Citak M, Kurtulus B, Duman E. The results of anterior fusion and CotrelDubousset-Hopf instrumentation in idiopathic scoliosis. Eur Spine J. 9(6):505-15.

6. Carreon LY, Puno RM, Lenke LG et al. Nonneurologic complications following surgery for adolescent idiopathic scoliosis. J Bone Joint Surg Am. 2007;89(11):2427-32.

7. Coe JD, Arlet V, Donaldson W, et al. Complications in spinal fusion for adolescent idiopathic scoliosis in the new millennium. A report of the Scoliosis Research Society Morbidity and Mortality Committee. Spine. 2006;31(3):345-9.

8. Robertson PA, Taylor TK. Late presentation of infection as a complication of Dwyer anterior spinal instrumentation. J Spinal Disord. 1993;6:256-259 9. van Luijk PJ, de Nies F. Recurrent scoliosis one year after surgical correction. Eur Spine J. 2011;20 Suppl 2:194.

10. Richards BS, Hasley BP, Casey VF. Repeat surgical interventions following "definitive" instrumentation and fusion for idiopathic scoliosis. Spine. 2006;31(26):3018-3026.

11. Sudo H, Ito M, Kaneda K, Shono Y, Abumi K. Long-term outcomes of anterior dual-rod instrumentation for thoracolumbar and lumbar curves in adolescent idiopathic scoliosis: a twelve to twenty-threeyear follow-up study. J Bone Joint Surg Am. 2013;95(8):e49.

12. Viola RW, King HA, Adler SM, Wilson CB. Delayed infection after elective spinal instrumentation and fusion. A retrospective analysis of eight cases. Spine. 1997;22(20):2444-51.
13. Di Silvestre M, Bakaloudis G, Lolli F, Giacomini S. Late-developing infection following posterior fusion for adolescent idiopathic scoliosis. Eur Spine J. 2011;20 Suppl 1:S121-7.

14. Verhulst FV, Goosen JMH, Meis JF, de Man FHR. Propionibacterium acnes infection in orthopedic surgery. Netherlands Journal of Orthopaedics. 2015;22(1):10-13.

15. Ohnishi T, Neo M, Matsushita M, Komeda M, Koyama T, Nakamura T. Delayed aortic rupture caused by an implanted anterior spinal device. Case report. J Neurosurg. 2001;95(2 Suppl):253-6.

16. Richards BR, Emara KM. Delayed infections after posterior TSRH spinal instrumentation for idiopathic scoliosis: revisited. Spine. 2001;26(18):1990-1996.

17. Soultanis KC, Pyrovolou N, Zahos KA et al. Late postoperative infection following spinal instrumentation: stainless steel versus titanium implants. J Surg Orthop Adv. 2008;17(3):193-9.

18. Kowalski TJ, Berbari EF, Huddleston PM, Steckelberg JM, Mandrekar JN, Osmon DR. The management and outcome of spinal implant infections: contemporary retrospective cohort study. Clin Infect Dis. 2007;44(7):913-920.

19. Gaine WJ, Andrew SM, Chadwick P, Cooke E, Williamson JB. Late operative site pain with isola posterior instrumentation requiring implant removal: infection or metal reaction? Spine.

2001;26(5):583-587.

20. Rihn JA, Lee JY, Ward WT. Infection after the surgical treatment of adolescent idiopathic scoliosis: evaluation of the diagnosis, treatment, and impact on clinical outcomes. Spine. 2008;33(3):289-294.

21. Bose B. Delayed infection after instrumented spine surgery: case reports and review of the literature. Spine J. 2003;3(5):394-399.

22. Clark CE, Shufflebarger HL. Late-developing infection in instrumented idiopathic scoliosis. Spine. 1999;24(18):1909-1912.

23. Collins I, Wilson-MacDonald J, Chami G, et al. The diagnosis and management of infection following instrumented spinal fusion. Eur Spine J. 2008;17(3):445-450.

24. Schwender JD, Casnellie MT, Perra JH, et al. Perioperative complications in revision anterior lumbar spine surgery: incidence and risk factors. Spine. 
2009;34(1):87-90.

25. Weis JC, Betz RR, Clements DH 3rd, Balsara RK. Prevalence of perioperative complications after anterior spinal fusion for patients with idiopathic scoliosis. J Spinal Disord. 1997;10(5):371-375.

\section{Disclosures}

The authors declare no relevant disclosures or conflicts of interest.

\section{Corresponding Author}

J.J. Tolk, Máxima Medical Centre, Department of Orthopedic Surgery. P.O. Box 90052, 5600 PD Eindhoven, the Netherlands. j.tolk@alumni.maastrichtuniversity.nl.

Published 7 January 2016.

This manuscript is generously published free of charge by ISASS, the International Society for the Advancement of Spine Surgery. Copyright $\odot 2016$ ISASS. To see more or order reprints or permissions, see http://ijssurgery.com. 